\title{
Morphometric variation in Loligo forbesi and Loligo vulgaris: regional, seasonal, sex, maturity and worker differences
}

Graham J. Pierce ${ }^{\mathrm{a},{ }^{*}}$, Lee C. Hastie ${ }^{\mathrm{b}}$, Angel Guerra ${ }^{\mathrm{c}}$, Roger S. Thorpe ${ }^{\mathrm{a} .1}$, F. Godfrey Howard $^{\text {b }}$, Peter R. Boyle ${ }^{\text {a }}$

a Department of Zoology, University of Aberdeen, Tillydrone Avenue, Aberdeen AB9 2TN, UK

${ }^{\mathrm{b}}$ Scottish Office Agriculture and Fisheries Department, PO Box 101, Victoria Road, Aberdeen AB9 8DB, UK

Instituto de Investigaciones Marinas (CSIC), Eduardo Cabello 6, 36208 Vigo, Spain

* Corresponding author.

${ }^{1}$ Present address: School of Biological Sciences, University College of North Wales, Bangor LL57 2UW, UK

\section{Abstract}

Morphometric variation in the squid Loligo forbesi was investigated to quantify effects of region, season, sex and maturity. Practical exercises were carried out using this species and the congeneric Loligo vulgaris to evaluate differences in measurements by different workers. The utility of meristic characters was also examined. Consistent significant differences were found between measurements by different workers, although this problem may be reduced with experience and many of the differences were small compared with observed differences between areas, particularly differences between Loligo forbesi from the Azores and elsewhere (Scotland, Spain, Portugal). Body shape in Loligo forbesi varied significantly in relation to maturity stage and, to a lesser extent, with season. Multivariate analysis of morphometric characters for samples collected in Scottish waters over 12 months revealed no consistent differences between localities. In contrast, there were marked differences between Loligo forbesi from the Azores and those from UK waters. If future studies on geographic variation in loliginids are to make use of morphometric characters, they should be based on simultaneous sampling to minimise effects of season and maturity, and all measurements on a single character should be made by a single worker.

Keywords: Loligo forbesi; Loligo vulgaris; Population structure; Seasonal dynamics 


\section{Introduction}

The veined squid Loligo forbesi is one of two loliginid species of commercial importance occurring in the northeastern Atlantic. Loligo forbesi is present throughout the northeastern Atlantic and its range extends to the west coast of Africa, the Mediterranean, and the Azores (Roper et al., 1984). The congeneric European squid, Loligo vulgaris, is less abundant in northern latitudes but increasingly replaces L. forbesi in the southern part of its range.

There are only two previously published studies on geographic variation in L. forbesi. Brierley et al. (1993) studied allozyme variation and found marked differences between Azores and UK samples. Boyle and Ngoile (1993) observed morphometric differences between specimens from the North Sea, northeast Atlantic and Rockall fishery areas (International Council for the Exploration of the Sea fishery subdivisions IV, VIa and VIb) but found no conclusive evidence of separate stocks. Both morphometric and allozyme data were used by Augustyn and Grant ( 1988 ) in a comparison of Loligo vulgaris vulgaris and Loligo vulgaris reynaudii, the study confirming that the differences were of subspecific rather than specific nature. Cohen (1976) examined morphometric characters of four species of Loligo forbesi from the western North Atlantic.

The application of multivariate analysis of morphometric data to studies on taxonomy and geographic variation is well-established for vertebrates, particularly reptiles (Thorpe, 1984; Thorpe and Baez, 1987; Thorpe and Brown, 1989; Butler et al., 1989; Creech, 1992), and has previously been extended to cephalopods in at least three studies (Kristensen, 1982; Augustyn and Grant, 1988; Boyle and Ngoile, 1993). However, softbodied animals present special problems with regard to measurements of body proportions and we believe that it is important to establish their reliability in studies of geographic variation. The present paper considers variation in morphometric and meristic characteristics of L. forbesi in Scottish waters and attempts to evaluate the relative importance of maturity state, season, and location as sources of variation. Sources of error, especially differences between measurements by different workers, are evaluated using L. forbesi and L. vulgaris, with a view towards the design of a study of 
geographic variation across the range of these species. Finally, some existing data on variation on a wider geographic scale are presented.

\section{Methods}

\subsection{Morphometric variation in UK samples}

From July 1990 to June 1991 samples of squid were obtained from the Scottish fishery. A box of squid was purchased every month from the west coast fishery, bought at the commercial market in Kinlochbervie. Additionally, squid caught by two small Aberdeen-based boats, the seiner 'Sunset' and the light trawler 'Trustful', were obtained as available. Squid were also obtained from research cruises by the Scottish Office Agriculture and Fisheries Department vessel 'Scotia'. The latter samples were frozen at sea. Commercial samples were normally stored on ice on the boat and during transport. The fishing area from which samples derive varied from month to month (Table 1). The gear used was also variable, but most samples were caught by demersal trawls. For analysis, the samples were classified into three broad regions, based on ICES fishery subdivisions. These were North Sea (IV), West coast (VIa) and Rockall (VIb).

Size-stratified sub-samples of approximately 30 males and 30 females (if available) were taken from each sample. Locally collected samples (area IV) were pooled on a monthly basis to achieve adequate sample sizes. All sub-sampled animals were stored at $-20^{\circ} \mathrm{C}$, in individually labelled polythene bags, for subsequent collection of detailed morphometric and meristic data.

Morphometric and meristic characters were selected and modified from those recommended by Roper and Voss (1983) and those used in previous studies (Augustyn and Grant, 1988; Boyle and Ngoile, 1993; L. Coelho, personal communication, 1990).

After thawing, measurements were taken in sequence as follows (Fig. 1): dorsal mantle length (ML), fin length (FL), fin width (FW), head length (HL), head width (HW), lengths of right arms 1, 2, 3, and 4 (LA1, LA2, LA3, LA4), length of the fight tentacle and tentacle club (TL, TCL), diameter of the largest sucker on the right tentacle club (LSD), mantle circumference (MC), lengths of the fight gill and fight funnel cartilage 
(GL, FCL), nuchal cartilage length (NCL), pen length (PL) and pen width (PW).

Measurements on arms, tentacle, gill and pen were made after removing the structure from the animal. Sucker rings were measured using a binocular microscope fitted with an eyepiece graticule ( 1 unit $=0.06 \mathrm{~mm}$ ) and all other measurements were taken with a ruler or vernier callipers (to $1 \mathrm{~mm}$ ).

Right arm 3, the right ventro-lateral buccal lappet, right tentacle club and right gill were removed and fixed in buffered formalin. Meristic data were later collected as follows: number of suckers on the buccal lappet, number of rows of suckers on the tentacle club, number of teeth on the largest sucker rings on the tentacle club and arm R3, number of gill lamellae. Maturity stage was also estimated on a scale of I-V (modified from Lipinski, 1979, after Ngoile, 1987; Lum-Kong, 1989; see Pierce et al., 1994a).

Data were screened for errors using bivariate lots and regression analyses to detect outliers. Erroneous values were corrected by reference to original data sheets or deleted.

Univariate and multivariate analyses were carried out to evaluate seasonal and regional trends, differences between sexes and maturity stages, and differences between measurements by different workers. Body size was normally controlled by using PL as a covariate. All statistical analyses made use of BMDP Statistical Software (Dixon et al., 1990).

\subsection{Experimental tests of worker differences}

To compare differences between morphometric measurements made by different workers, 24 squid (Loligo vulgaris) were measured by four workers (GJP, C. Martins, F. Porteiro, J. Pereira). The use of Loligo vulgaris was dictated by availability in Lisbon where the exercise was conducted. Each worker made a set of measurements on an animal, then moved on to the next animal. Systematic errors due to repeated handling were effectively controlled for by this experimental design since each person was first, second, third and fourth to measure equal numbers of squid. Some measurements could not be made completely independently since the first person necessarily removed the structure to measure it. Thus, differences due to cutting arms and gills at different points could not be fully assessed. 
In a separate exercise, meristic data were collected from fixed tissues of ten Loligo forbesi by seven workers (LCH, J. Pereira, C. Martins, F. Porteiro, M. Cunha, F. Casas, M. T. Fernandez).

Measurements on samples of Loligo forbesi and Loligo vulgaris collected during February-April 1991 by workers based in Vigo, Barcelona (Spain), Lisbon, Faro (Portugal) and the Azores (see Table 2) were analysed in conjunction with contemporaneous samples from Aberdeen to evaluate the magnitude of apparent regional differences in relation to worker differences.

\subsection{Regional variation in Loligo forbesi}

We also analysed morphometric data on Loligo forbesi from the UK and the Azores collected in 1989 by AG and FGH. Between May and October 1989, samples were collected from Sao Jorge Island (Azores), the Moray Firth, Rockall Bank and Humber (Table 2). The Azores samples were caught by commercial jigging during daylight hours. UK samples were caught by commercial and research vessels using demersal trawls. Although there is extensive overlap in size and maturity between areas, a higher proportion of the Azores sample was mature and the Azores animals were larger. All squid were stored frozen between receipt and collection of morphometric data. All measurements were taken by AG or FGH, with both workers measuring animals from both areas.

The following morphometric characters were measured: ML, FL, FW, HW, mantle width, lengths of right arms $1,2,3$, and 4, length of the right tentacle and tentacle club, diameter of the largest sucker on the right tentacle club, length of the hectocotylised arm in males, PL. Six beak characters were also recorded: upper beak hood length (UHL), upper beak crest length (UCL), upper beak height (UHT), lower beak hood length (LHL), lower beak crest length (LCL) and lower beak height (LHT). Beak dimensions and the diameter of the largest sucker were measured with callipers, to the nearest 0.1 $\mathrm{mm}$, and all other measurements were made with a ruler, to the nearest $1 \mathrm{~mm}$. 
Beak and body measurements were analysed separately, as were data from males and females. After screening for errors, body measurements were corrected for the effect of body size using regression coefficients from pooled within-group regressions on ML. (PL was not used owing to relatively large numbers of specimens having broken pens). All measurements except ML were thus transformed to their predicted value for an animal of average (overall mean) ML. Beak measurements were similarly corrected for size using regression coefficients from pooled within-group regressions on LCL. Transformed data were entered into canonical variates analysis (a) excluding the size character (ML or LCL; 'size out') and (b) using all characters including size ('size in').

\section{Results}

\subsection{Worker differences}

A two-way ANOVA for morphometric characters of the 24 Loligo vulgaris showed significant differences between measurements by different workers for more than half of the variables examined (Table A 1 ). Measurements of ML differed significantly between workers, whereas measurements of pen length (PL) did not, justifying the use of PL as covariate in all subsequent analyses. Average differences between workers were quantified by calculating regressions on PL (all data pooled) and calculating mean residuals for each worker. Two workers, GJP and CM, consistently recorded lower values than the other two, JP and FP (Table A2).

Analysis of meristic data from ten Loligo forbesi indicates significant differences between workers for four out of five variables (Table A3). However, it was noted that fixed tissues deteriorated with repeated handling and the analysis was therefore repeated using only the first four sets of data from each specimen. Significant differences remained between workers for three variables.

\subsection{Worker differences vs. regional differences}

ANCOVA of data on male Loligo forbesi collected in all areas during February-May 1991 (Table A4) indicated that for all variables, size-adjusted group means differed significantly between areas $(\mathrm{P}<0.001)$, but for all variables except FL there were also 
significant between-area differences in regression slope $(\mathrm{P}<0.05)$. The latter result suggests that the effect of body size is not completely removed by regression on PL. (Nevertheless, the relationships are sufficiently close to linear that simple transformations, e.g. logarithmic, square root, do not result in improved linearisation.) Consequently, residuals will include three components: area difference in size-removed residual, area difference in slope, and worker difference. For female Loligo forbesi (Table A5), there were also significant differences between areas in size-adjusted group means for all variables $(\mathrm{P}<0.001)$. However, there were fewer significant differences in regression slopes than for males; for the variables LA1, LA2, TL, TCL, LSD, GL, FCL and PW $(\mathrm{P}<0.05)$. For male Loligo vulgaris (Table A6), there were significant between-area differences in group means for all variables except FCL $(\mathrm{P}<0.05)$ and only one significant between-area difference in regression slopes, for $\mathrm{HW}(\mathrm{P}<0.05)$. For female Loligo vulgaris (Table A7), there were significant between-area differences in group means for all variables except FL, FCL and NCL $(\mathrm{P}<0.05)$ and significant between-area differences in regression slopes for LA 1, TL, TCL, LSD and PW $(\mathrm{P}<0.05)$.

Results from pooled within-group regressions (Tables A8 and A9) indicated that differences between Loligo forbesi from different areas were of considerably greater magnitude than those expected due to worker effects alone for most variables (Table A2), and Loligo forbesi from the Azores differed markedly from the other samples. Differences between areas were generally smaller for Loligo vulgaris than for Loligo forbesi, and closer in magnitude to differences expected due to worker effects alone.

\subsection{Morphometric variation in Scottish waters}

The west coast (area IV) was the best represented area in the UK samples and analysis of seasonal differences in morphometry was restricted to samples from this area. For each morphometric variable, a four-way analysis of covariance was carded out. Size effects were removed using PL as a covariate. The four grouping factors considered were: season (January-April, May-August, September-December), worker (GJP and LCH), sex (male, female) and maturity ('Immature' I and II, 'Mature III-V'). These broad classes were necessary to ensure a balanced design (Table A10). 
There were significant season and maturity differences for most variables. Worker differences were significant for only four variables, two of which showed no seasonal variation. Sex differences were significant for a number of variables, particularly pen width, mantle circumference and fin width, reflecting the wider female body form. Interaction terms are not presented but some were significant. These results suggest that any further analysis of seasonal variation within regions should be carried out separately for males and females and for different maturity stages. Depending on the variables used it may also be necessary to treat each worker's data separately. Furthermore, regional variation should ideally be examined using samples collected over the same time period.

To determine whether any of the significant effects could be regressed out, stepwise multiple linear regression analysis was applied to the west coast data. Seasonal differences were included by assigning each sample to a calendar month, maturity was expressed as testis length (males) or nidamental gland length (females), and 'worker' was coded as 1 (GJP) or 2 (LCH). For males (Table A11), worker differences were apparent for only four variables. Two of the coefficients were negative and two positive, indicating that there was no overall tendency for one person to produce consistently high or consistently low values. Coefficients for month were always positive, suggesting that body parts were larger, relative to body length, later in the year, and coefficients for testis length were always negative indicating that body parts increased in size at a slower rate than overall body length as animals matured. The pattern was similar in data from females (Table A12), although there were more (seven) significant between-worker differences, and pen width showed opposite trends to those observed for other variables in relation to month and maturity.

\subsection{Regional variation in Scottish waters}

To investigate the extent of regional variation in relation to other sources of variation, the entire Scottish data set for July 1990-June 1991 was used. Each large sample was treated as a separate group and smaller samples from the same month and area were grouped together. The very small east coast samples for December 1990, February, March, May and June 1991 were not used. This resulted in a total of 18 groups, each referring to one locality and 1 month. Analysis was restricted to males measured by GJP 
or LCH, thus minimising between worker variation. Analyses of covariance indicated that, while differences between adjusted group means were highly significant, slopes of regressions on PL differed significantly between groups (Table A13). Use of testis length as an additional covariate was of little value since the associated regression coefficient was generally non-significant and slopes remained significantly different. (It is probable that seasonal and maturity differences are confounded.)

Canonical variates analysis was carried out after correcting measurements for size using pooled within-group regression coefficients (Fig. 2). The correction was not completely satisfactory owing to the differences in slopes. The analysis was repeated excluding tentacle data to reduce the number of specimens lost owing to missing data (Fig. 3). The location of group means on the first axis (CV1) is similar for both analyses. No one group stands out as distinct, and west coast samples from March and September lie at opposite ends of the axis. Standardised coefficients for canonical variables (Table A14) indicate that mantle circumference had the strongest influence on CV1, while several variables contributed similarly to CV2. Mantle circumference was the variable most strongly affected by maturity (Table A10) and the separation on CV1 may therefore relate largely to maturity. There was some separation of samples from different regions, particularly the September 1990 samples from the east coast, west coast, and Rockall. There was also partial separation of east and west coast samples on axis 2 in Fig. 2 (but not Fig. 3). Overall, however, there were no consistent regional differences.

\subsection{Differences between UK and Azores samples}

There were significant between-area differences in regression slopes for the majority of variables. Comparison of 'size-in' and 'size-out' canonical variates analyses (Table 3) indicates that differences between Azores and UK samples are accentuated by inclusion of body size but, even with effects of size removed (as far as possible), the Azores sample is well-separated from the UK samples in its score on the first canonical axis. The differences are apparent for both males and females, from both body and beak measurements.

\section{Discussion}


Differences between measurements by different workers represent a potentially serious problem for the conduct of studies of geographic variation based on morphometric data. In the present study, differences between workers were apparent in both morphometric and meristic data. Some workers consistently measure 'short' and others 'long'. In a softbodied animal, many body parts are prone to stretching, which may exacerbate the problem. To some extent these problems will be reduced by training and experience, although it should be noted that the workers involved in the present exercise were all experienced to varying degrees and working to a set of procedures arising from prior agreement. For the Scottish west coast samples, worker differences were apparent for only four of the morphometric variables measured by the two most experienced workers (GJP and LCH). Studies on fish otoliths have shown that between-reader bias in counting rings is more of a problem for inexperienced workers (Kimura and Lyons, 1991). Nevertheless, to ensure comparable data it is preferable for each character or set of characters to be measured on all specimens by a single worker.

In Loligo forbesi it was apparent that the effect of body size on body shape could not easily be regressed out. Relationships between PL and other measurements were, however, sufficiently close to linear that simple transformations invariably produced curvilinear relationships. Loligo forbesi has a very wide range of adult body size, particularly in males, with animals reaching a larger size in the Azores than elsewhere (Martins, 1982). Thus, apparent differences in body form between the Azores and elsewhere could be generated as an artefact of failure to completely remove the effect of size. The absence of small animals from the Azores means that we cannot fully specify the form of the relationships between ML and other measurements in this area. It is possible that across the full range of body sizes the relationship is basically non-linear, and that at small body sizes the regression slopes would be similar to those for squid from other areas. In contrast, in Loligo vulgaris, which has a smaller range of adult body sizes, the effect of body size on other measurements could normally be successfully regressed out. In a study on morphometric variation in Gonatus fabricii, Kristensen (1982) attempted to control for differences in body size by using ratios between pen length and other measurements. This is a generally less satisfactory procedure if there is any allometry (Thorpe, 1976). If the underlying regression of a measurement on pen length is non-linear or has a non-zero intercept, merely dividing by pen length does not successfully control for size. 
Analysis of morphometric variation in the Scottish samples of Loligo forbesi revealed clear effects of season and, particularly, maturity on body shape. Regression coefficients of body measurements on indices of maturity (testis length, nidamental gland length), having regressed out body size (PL) and season, were invariably negative, consistent with a shift from growth of somatic body components to growth of reproductive structures in more mature animals. A clear recommendation thus arises that studies of geographic variation on this species should be based on contemporaneous samples with similar levels of maturity.

Canonical variates analysis on morphometric data collected over 12 months for Scottish Loligo forbesi suggested that variation was dominated by seasonal and maturity differences, with no consistent differences between regions (east coast, west coast, Rockall) apparent. Boyle and Ngoile (1993) found differences in body form between Scottish Loligo forbesi from different regions, but no clear evidence of separate populations. It is probable in such a highly mobile species that there is free movement between all parts of the Scottish coast, so that separate regional populations are unlikely. However, this may not apply to squid at Rockall, which is approximately 400 $\mathrm{km}$ from the coast.

For both Loligo species, there were differences in morphometric measurements between samples from different areas on the continental shelf, but worker effects cannot be ruled out as an explanation. The largest differences observed in these samples from April 1991 were, however, between Loligo forbesi from the Azores and elsewhere.

The existence of significant differences in body form of Loligo forbesi between the Azores and Scotland is strongly supported by the data collected in 1989, for which worker effects can be discounted, although, because the sampling was over an extended period, seasonal and maturity differences cannot be ruled out and the problem of effectively removing size differences remains. Nevertheless, the result is consistent with Brierley et al.'s (1993) results on allozymic variation, which showed that most UK samples were genetically indistinguishable and were distinct from Azores animals. 
A full evaluation of geographic variation in Loligo forbesi requires samples from across the range, including the Spanish and Portuguese mainland coasts, collected simultaneously and the data recorded so as to eliminate worker effects. Results of such a study, designed in the light of results presented here, appear in Pierce et al. (1994b) and Brierley et al. (1994).

\section{Acknowledgements}

This work was funded by the Commission of the European Communities within the frame of the EEC research programme in the fisheries sector (FAR, Contract No. MA 1.146). Data collection by AG and FGH in 1989 was supported by the Spanish Ministry of Education and Science and the British Council under the British/Spanish Joint Research Programme (Acciones Integradas 1989/90). C. Sousa-Reis provided facilities for practical work at the Instituto Português de Investigaçao Maritima, Lisbon. F. Casas, M. Cunha, M. T. Fernandez, C. Martins, J. Pereira and F. Porteiro participated in data collection. S. Adams, A.P. Cabaleiro, C. Chapman, T. Craig, S. Hoskin, the skippers of 'Sunset' and 'Trustful', Kinlochbervie Fishery Office and Kinlochbervie Fish Selling Co. assisted with sample collection.

\section{References}

Augustyn, C.J. and Grant, W.S., 1988. Biochemical and morphological systematics of Loligo vulgaris vulgaris Lamarck and Loligo vulgaris reynaudii d'Orbigny Nov Comb (Cephalopoda: Myopsida). Malacologia, 29: 215-233.

Boyle, P.R. and Ngoile, M.A.K., 1993. Population variation and growth in Loligo forbesi (Cephalopoda: Loliginidae) from Scottish waters. In: T. Okutani, R. O'Dor and T. Kubodera (Editors), Recent Advances in Cephalopod Fisheries Biology. Tokai University Press, Tokyo, pp. 49-59.

Brierley, A.S., Thorpe, J.P., Clarke, M.R. and Martins, H.R., 1993. A biochemical genetic investigation of the population structure of Loligo forbesi Steenstrup, 1856 from the British Isles and the Azores. In: T. Okutani, R. O'Dor and T. Kubodera (Editors), Recent Advances in Cephalopod Fisheries Biology. Tokai University Press, Tokyo, pp. 61-70. 
Brierley, A., Thorpe, J., Pierce, G.J., Clarke, M.R., Boyle, P.R., 1994. Genetic variation in Loligo forbesi in the Northeast Atlantic. Mar. Biol., in press.

Butler, P.M., Thorpe, R.S. and Greenwood, M., 1989. Interspecific relations of African crocidurine shrews (Mammalia: Soricidae) based on multivariate analysis of mandibular data. Zool. J. Linn. Soc., 96: 373-412.

Cohen, A.C., 1976. The systematics and distribution of Loligo (Cephalopoda, Myopsida) in the western North Atlantic, with descriptions of two new species. Malacologia, 15: 299-367.

Creech, S., 1992. A multivariate morphometric investigation of Atherina boyeri Risso, 1810 and A. presbyter Cuvier, 1829 (Teleostei: Atherinidae): morphometric evidence in support of the two species. J. Fish. Biol., 41: 341-353.

Dixon, W.J., Brown, M.B., Engelman, L. and Jennrich, R.I., 1990. BMDP Statistical Software Manual. 2 vols. University of California Press, Berkeley.

Kimura, D.K. and Lyons, J.J., 1991. Between-reader bias and variability in the agedetermination process. Fish. Bull., 89: 53-60.

Kristensen, T.K., 1982. Multivariate statistical analysis of geographic variation in the squid Gonatus fabricii Lichtenstein 1818) (Mollusca: Cephalopoda). Malacologia, 22:581-586.

Lipinski, M., 1979. Universal maturity scale for the commercially important squids. The results of maturity classification of lllex illecebrosus (Lesueur, 1821) population for years 1973-1977. Res. Doc. 79/II/38. Serial No. 5364, International Commission for the Northwest Atlantic Fisheries, 40 pp.

Lum-Kong, A., 1989. The reproductive biology of female Loligo forbesi Steenstrup (Cephalopoda: Myopsida). Ph.D. Thesis, University of Aberdeen.

Martins, H.R., 1982. Biological studies on the exploited stock of Loligo forbesi (Mollusca: Cephalopoda) in the Azores. J. Mar. Biol. Assoc. UK, 62: 799-808. Ngoile, M.A.K., 1987. Fishery biology of the squid Loligo forbesi (Cephalopoda: Loliginidae) in Scottish waters. Ph.D. Thesis, University of Aberdeen. Pierce, G.J., Boyle, P.R., Hastie, L.C. and Key, L., 1994a. The life history of Loligo forbesi (Cephalopoda: Loliginidae) in Scottish waters. Fish. Res., 21:17-41. Pierce, G.J., Thorpe, R.S., Hastie, L.C., Brierley, A.S., Guerra, A., Boyle, P.R., Jamieson, R. and Avila, P., 1994b. Geographic variation in Loligo forbesi in the northeast Atlantic. Mar. Biol., 119: 541-547. 
Roper, C.F.E. and Voss, G.L., 1983. Guidelines for taxonomic descriptions of cephalopod species. Mere. Nat. Mus. Vic., 44: 48-63.

Roper, C.F.E., Sweeney, M.J. and Nauen, C.E., 1984. Cephalopods of the World. An Annotated and Illustrated Catalogue of Species of Interest to Fisheries. Fisheries Synopsis 125, Vol. 3, FAO, Rome, 277 pp.

Thorpe, R.S., 1976. Biometric analysis of geographic variation and racial affinities. Biol. Rev., 51: 407-452.

Thorpe, R.S., 1984. Geographic variation in the western grass snake (Natrix natrix helvetica) in relation to hypothesized phylogeny and conventional subspecies. J. Zool. London, 203: 345-355.

Thorpe, R.S. and Baez, M., 1987. Geographic variation within an island: univariate and multivariate contouring of scalation, size, and shape of the lizard Galliota galloti. Evolution, 41: 256-268.

Thorpe, R.S. and Brown, R.P., 1989. Microgeographic variation in the colour pattern of the lizard Galliota galloti within the island of Tenerife: distribution, pattern and hypothesis testing. Biol. J. Linn. Soc., 38: 303-322. 
Table 1

Numbers of Loligo forbesi sub-sampled for morphometric data at Aberdeen, July 1990-

October 1991, plus size and maturity stage data

\begin{tabular}{|c|c|c|c|c|c|c|c|}
\hline \multirow[t]{2}{*}{ Date } & \multirow[t]{2}{*}{ Sampling area } & \multicolumn{3}{|c|}{ Males } & \multicolumn{3}{|c|}{ Females } \\
\hline & & $\mathrm{N}$ & ML & Stage & $\mathrm{N}$ & ML & Stage \\
\hline \multirow[t]{2}{*}{$7 / 1990$} & Aberdeen & 12 & 84-195 & I-II & 10 & $65-278$ & $\mathrm{I}-\mathrm{V}$ \\
\hline & North Rona & 25 & $146-375$ & II-V & 44 & $136-258$ & $\mathrm{I}-\mathrm{V}$ \\
\hline \multirow[t]{2}{*}{ 8/1990 } & Aberdeen & 16 & $185-308$ & I-II & 4 & $110-188$ & I-II \\
\hline & Minch & 36 & $121-333$ & l-IV & 32 & $152-258$ & II-IV \\
\hline \multirow[t]{3}{*}{ 9/1990 } & Aberdeen & 30 & $140-390$ & $\mathrm{I}-\mathrm{V}$ & 10 & 138-295 & II-V \\
\hline & West Coast & 30 & $190-425$ & II-V & 34 & $169-249$ & II-III \\
\hline & Rockall $^{\mathrm{r}}$ & 41 & $125-439$ & $\mathrm{I}-\mathrm{V}$ & 44 & $154-237$ & I-III \\
\hline $10 / 1990$ & Aberdeen & 31 & $110-384$ & $\mathrm{I}-\mathrm{V}$ & 26 & $88-259$ & I-III \\
\hline \multirow[t]{3}{*}{$11 / 1990$} & Cape Wrath & 42 & $130-248$ & $\mathrm{I}-\mathrm{V}$ & 31 & $119-277$ & I-III \\
\hline & Aberdeen & 17 & $185-410$ & II-V & 19 & $155-263$ & II-IV \\
\hline & Solan Bank & 31 & $180-330$ & II-V & 30 & $118-310$ & $\mathrm{I}-\mathrm{V}$ \\
\hline \multirow[t]{2}{*}{$12 / 1990$} & Aberdeen & 6 & $271-481$ & III-V & 2 & 206-295 & IV-V \\
\hline & Sula Sgeir & 33 & $108-346$ & $\mathrm{I}-\mathrm{V}$ & 32 & $121-327$ & $\mathrm{I}-\mathrm{V}$ \\
\hline $1 / 1991$ & Aberdeen & 36 & $182-417$ & II-V & 41 & $148-315$ & II-V \\
\hline \multirow[t]{2}{*}{ 2/1991 } & Aberdeen & 3 & $313-452$ & V & 3 & $225-255$ & IV-V \\
\hline & Butt of Lewis & 30 & $136-318$ & $\mathrm{I}-\mathrm{V}$ & 30 & $161-300$ & II-V \\
\hline \multirow[t]{2}{*}{ 3/1991 } & Aberdeen & 2 & $265-356$ & II-V & 0 & - & - \\
\hline & Butt of Lewis & 30 & $140-373$ & III-V & 29 & $189-312$ & IV-V \\
\hline 4/1991 & North Rona & 34 & 132-392 & $\mathrm{I}-\mathrm{V}$ & 38 & $107-293$ & $\mathrm{I}-\mathrm{V}$ \\
\hline \multirow[t]{2}{*}{ 5/1991 } & Aberdeen & 0 & - & - & 1 & 215 & IV \\
\hline & Sule Skerry & 35 & $133-434$ & $\mathrm{I}-\mathrm{V}$ & 35 & $171-322$ & III-V \\
\hline \multirow[t]{2}{*}{ 6/1991 } & Aberdeen & 5 & $265-370$ & $\mathrm{~V}$ & 0 & - & - \\
\hline & North Rona & 36 & 139-299 & $\mathrm{I}-\mathrm{V}$ & 28 & $119-243$ & $\mathrm{I}-\mathrm{V}$ \\
\hline
\end{tabular}

Samples were from commercial boats except those marked with a superscript (r), which were research samples.

Table 2

Numbers of Loligo sampled for morphometric measurements, 1989 and 1991 


\begin{tabular}{|c|c|c|c|c|c|c|}
\hline \multirow[t]{2}{*}{ Area } & \multicolumn{3}{|c|}{ Males } & \multicolumn{3}{|c|}{ Females } \\
\hline & $\mathrm{N}$ & ML & Stage & $\mathrm{N}$ & ML & Stage \\
\hline \multicolumn{7}{|c|}{ (i) Samples of Loligo forbesi collected in February-April 1991} \\
\hline Aberdeen & 99 & $132-452$ & $\mathrm{I}-\mathrm{V}$ & 100 & $107-312$ & $\mathrm{I}-\mathrm{V}$ \\
\hline Vigo & 34 & $101-270$ & $\mathrm{I}-\mathrm{V}$ & 15 & 118-355 & $\mathrm{I}-\mathrm{V}$ \\
\hline Lisbon & 40 & $67-213$ & I-II & 35 & 64-202 & I-II \\
\hline Azores & 79 & $347-841$ & III-V & 55 & $275-438$ & III-V \\
\hline \multicolumn{7}{|c|}{ (ii) Samples of Loligo vulgaris collected in February-April 1991} \\
\hline Aberdeen & 1 & 205 & III & 0 & - & - \\
\hline Vigo & 25 & $110-350$ & $\mathrm{I}-\mathrm{V}$ & 21 & $88-220$ & $\mathrm{I}-\mathrm{V}$ \\
\hline Lisbon & 9 & $53-144$ & I-IV & 16 & $60-254$ & I-IV \\
\hline Algarve & 94 & $122-479$ & $\mathrm{I}-\mathrm{V}$ & 46 & $100-295$ & $\mathrm{I}-\mathrm{V}$ \\
\hline Barcelona & 8 & $105-143$ & II-IV & 6 & $164-240$ & III-IV \\
\hline \multicolumn{7}{|c|}{ (iii) Samples of Loligo forbesi from the UK and the Azores, May-October 1989} \\
\hline Moray Firth & 166 & $52-499$ & $\mathrm{I}-\mathrm{V}$ & 90 & $42-242$ & $\mathrm{I}-\mathrm{V}$ \\
\hline Rockall & 52 & $108-401$ & $\mathrm{I}-\mathrm{V}$ & 90 & 98-399 & $\mathrm{I}-\mathrm{V}$ \\
\hline Humber & 74 & $101-361$ & I-IV & 34 & $76-323$ & I-IV \\
\hline Azores & 132 & 246-890 & $\mathrm{I}-\mathrm{V}$ & 193 & $235-408$ & IV-V \\
\hline
\end{tabular}

Table 3

Canonical variates analysis of 1989 Loligo forbesi samples: scores in first canonical variable for 'sizein' and 'size-out' analyses

\begin{tabular}{|c|c|c|c|c|c|c|c|c|}
\hline \multirow[t]{3}{*}{ Area } & \multicolumn{4}{|c|}{ Body measurements } & \multicolumn{4}{|c|}{ Beak measurement } \\
\hline & \multicolumn{2}{|l|}{ Males } & \multicolumn{2}{|c|}{ Females } & \multicolumn{2}{|l|}{ Males } & \multicolumn{2}{|c|}{ Females } \\
\hline & 'Out' & 'In' & 'Out' & 'In' & 'Out' & 'In' & 'Out' & 'In' \\
\hline Moray Firth & 1.10 & 1.79 & 1.88 & 3.20 & 0.40 & 1.49 & 0.95 & 3.02 \\
\hline Rockall & 0.65 & 0.94 & 0.88 & 1.87 & 0.87 & 0.76 & 1.17 & 2.02 \\
\hline Humber & 0.81 & 1.40 & 1.59 & 2.92 & 0.26 & 0.93 & 0.93 & 2.51 \\
\hline Azores & -2.21 & -3.58 & -1.66 & -3.05 & -1.08 & -2.96 & -1.18 & -2.88 \\
\hline
\end{tabular}


Fig. 1. Morphometric measurements taken on Loligo forbesi and Loligo vulgaris specimens.

Fig. 2. Results of canonical variates analysis for all year 1 samples from Aberdeen (males only). Group means are plotted against CV1 and CV2. All morphometric variables (excluding pen length) were used. Groups are identified by locality (E, east; W, west; R, Rockall) and month (1-12).

Fig. 3. Results of canonical variates analysis for all year 1 samples from Aberdeen (males only). Group means are plotted against CV1 and CV2. Tentacle variables (and pen length) were excluded. Groups are identified by locality (E, east; W, west; R, Rockall) and month (1-12).

Appendix

Table A 1

Worker differences: analysis of variance for morphometrics

\begin{tabular}{lllll}
\hline Variable & $\mathrm{N}$ & d.f. & $\mathrm{F}$ & $\mathrm{P}$ \\
\hline Body weight & 94 & 3,67 & 1.05 & 0.374 \\
ML & 96 & 3,69 & 7.82 & $<0.0001^{* * *}$ \\
Fin length & 96 & 3,69 & 1.87 & 0.144 \\
Fin width & 96 & 3,69 & 29.53 & $<0.0001^{* * *}$ \\
Head length & 96 & 3,69 & 15.57 & $<0.0001^{* * *}$ \\
Head width & 96 & 3,69 & 17.66 & $<0.0001^{* * *}$ \\
Arm R1 length & 96 & 3,69 & 10.03 & $<0.0001^{* * *}$ \\
Arm R2 length & 92 & 3,69 & 16.95 & $<0.0001^{* * *}$ \\
Arm R3 length & 96 & 3,69 & 22.58 & $<0.0001^{* * *}$ \\
Arm R4 length & 96 & 3,69 & 22.95 & $<0.0001^{* * *}$ \\
Tentacle length & 96 & 3,69 & 7.55 & $0.0002^{* * *}$ \\
Club length & 87 & 3,62 & 11.84 & $<0.0001^{* * *}$ \\
Sucker diameter & 88 & 3,63 & 0.89 & 0.449 \\
Mantle circumference & 95 & 3,68 & 2.20 & 0.096 \\
Gill length & 94 & 3,67 & 0.58 & 0.631 \\
\hline
\end{tabular}




\begin{tabular}{lllll}
\hline Funnel cartilage length & 95 & 3,68 & 16.64 & $<0.0001^{* * *}$ \\
Nuchal cartilage length & 95 & 3,68 & 7.47 & $0.0002^{* * *}$ \\
Pen length & 95 & 3,68 & 0.54 & 0.658 \\
Pen width & 95 & 3,68 & 0.78 & 0.511 \\
Mantle weight & 95 & 3,68 & 1.08 & 0.363
\end{tabular}

In a two-way analysis of variance, the difference between specimens was always significant $(\mathrm{P}<0.0001)$.

*** $\mathrm{P}<0.001$.

Table A2

Worker differences: analysis of residuals for morphometrics

\begin{tabular}{|c|c|c|c|c|}
\hline \multirow[t]{2}{*}{ Variable } & \multicolumn{4}{|c|}{ Worker No. $^{a}$} \\
\hline & 1 & 2 & 3 & 4 \\
\hline $\mathrm{ML}^{*}$ & $-0.21 \pm 1.51$ & $-1.42 \pm 1.87$ & $2.62 \pm 1.45$ & $-1.05 \pm 1.57$ \\
\hline Fin length & $-0.27 \pm 0.95$ & $-1.51 \pm 1.14$ & $0.69 \pm 0.80$ & $0.49 \pm 1.03$ \\
\hline Fin width* & $-3.97 \pm 2.48$ & $-3.53 \pm 2.90$ & $4.57 \pm 2.87$ & $2.78 \pm 2.85$ \\
\hline Head length* & $-0.71 \pm 1.16$ & $-1.97 \pm 1.26$ & $-0.07 \pm 1.29$ & $2.66 \pm 1.32$ \\
\hline Head width* & $-0.71 \pm 0.40$ & $-1.15 \pm 0.34$ & $1.50 \pm 0.39$ & $0.33 \pm 0.54$ \\
\hline Arm Rl length* & $-1.55 \pm 2.27$ & $-0.76 \pm 2.31$ & $0.44 \pm 2.15$ & $1.84 \pm 2.23$ \\
\hline Arm R2 length* & $-1.79 \pm 2.95$ & $0.05 \pm 3.16$ & $0.82 \pm 2.79$ & $0.92 \pm 2.88$ \\
\hline Arm R3 length* & $-2.80 \pm 3.00$ & $-1.53 \pm 3.24$ & $2.13 \pm 2.87$ & $2.14 \pm 2.96$ \\
\hline Arm R4 length* & $-2.19 \pm 2.51$ & $-1.60 \pm 2.88$ & $2.16 \pm 2.46$ & $1.57 \pm 2.57$ \\
\hline Tentacle length* & $-1.13 \pm 0.85$ & $-0.50 \pm 0.98$ & $1.50 \pm 1.04$ & $0.11 \pm 0.83$ \\
\hline Club length* & $-5.01 \pm 6.12$ & $3.80 \pm 6.56$ & $1.97 \pm 6.61$ & $-0.61 \pm 6.62$ \\
\hline Sucker diameter & $-0.58 \pm 0.13$ & $-0.07 \pm 0.15$ & $0.50 \pm 0.14$ & $0.15 \pm 0.18$ \\
\hline Mantle circumference & $-0.79 \pm 1.38$ & $-0.57 \pm 1.31$ & $0.80 \pm 1.23$ & $0.57 \pm 1.43$ \\
\hline Gill length & $-0.38 \pm 1.01$ & $-0.41 \pm 1.07$ & $0.69 \pm 0.69$ & $0.10 \pm 0.77$ \\
\hline Funnel cart. length* & $-1.03 \pm 0.50$ & $-0.67 \pm 0.51$ & $1.11 \pm 0.40$ & $0.60 \pm 0.55$ \\
\hline Nuchal cart. length* & $-0.03 \pm 0.58$ & $-1.01 \pm 0.67$ & $0.59 \pm 0.49$ & $0.43 \pm 0.63$ \\
\hline Pen width & $-0.24 \pm 0.57$ & $0.02 \pm 0.45$ & $0.10 \pm 0.44$ & $0.12 \pm 0.52$ \\
\hline
\end{tabular}

a1, GJP; 2, cm; 3, JP; 4, FP. 
For each variable, all measurements were pooled and regressed on pen length. Residuals for each worker are summarised as mean $\pm 1 \mathrm{SE}^{*}$ denotes significant differences identified by ANOVA (Table 6).

Table A3

Worker differences: analysis of variance for meristics

\begin{tabular}{lclll}
\hline Variable & $\mathrm{N}$ & d.f. & $\mathrm{F}$ & $\mathrm{P}$ \\
\hline (a) All data & & & & \\
SRTC & 62 & 6,46 & 4.86 & $0.0006^{* * *}$ \\
DTC & 60 & 6,44 & 5.82 & $0.0002^{* * *}$ \\
DR3 & 62 & 6,46 & 1.91 & 0.099 \\
SBL & 61 & 6,45 & 3.85 & $0.0035^{* *}$ \\
GL & 62 & 6,46 & 2.89 & $0.0178^{*}$ \\
(b) Ist 4 measurements & & & \\
SRTC & 38 & 6,22 & 3.25 & $0.0193^{*}$ \\
DTC & 38 & 6,22 & 3.19 & $0.0209^{*}$ \\
DR3 & 38 & 6,22 & 1.60 & 0.1932 \\
SBL & 38 & 6,22 & 2.34 & 0.0673 \\
GL & 38 & 6,22 & 2.82 & $0.0345^{*}$
\end{tabular}

In a two-way analysis of variance, the difference between specimens was significant $(\mathrm{P}<0.01)$ for all variables except SRTC. Differences between workers are tabulated. Variables are: number of sucker rows on tentacular club (SRTC), number of denticles on the largest sucker ring on the tentacular club (DTC), number of denticles on the largest sucker ring on arm 3 (DR3), number of suckers on the ventro-lateral buccal lappet (SBL), number of gill lamellae (GL)

$* \mathrm{P}<0.05 ; * * \mathrm{P}<0.01 ; * * * \mathrm{P}<0.001$.

\section{Table A4}

Analysis of covariance for morphometrics: male Loligo forbesi from February-April samples. Pen length is used as the covariate. For all variables, the table shows sample size, F-values and probabilities for tests of equality of adjusted means and equality of regression slopes. Probabilities are given to three decimal places. Pooled within-group regression coefficients are also given 


\begin{tabular}{lllllll}
\hline Variable & $\mathrm{N}$ & Means & & Slopes & Regression \\
& & $\mathrm{F}$ & $\mathrm{P}$ & $\mathrm{F}$ & $\mathrm{P}$ & coefficient \\
\hline Fin length & 244 & 11.099 & 0.000 & 1.155 & 0.328 & 0.67336 \\
Fin width & 240 & 68.485 & 0.000 & 3.924 & 0.009 & 0.41168 \\
Head length & 242 & 185.271 & 0.000 & 6.747 & 0.000 & 0.07881 \\
Head width & 227 & 19.555 & 0.000 & 7.435 & 0.000 & 0.05317 \\
Arm 1 length & 238 & 128.460 & 0.000 & 9.491 & 0.000 & 0.17532 \\
Arm 2 length & 233 & 106.657 & 0.000 & 7.792 & 0.000 & 0.21041 \\
Arm 3 length & 229 & 88.913 & 0.000 & 5.043 & 0.002 & 0.22672 \\
Arm 4 length & 239 & 91.588 & 0.000 & 7.348 & 0.000 & 0.18033 \\
Tentacle length & 207 & 51.880 & 0.000 & 16.218 & 0.000 & 0.51528 \\
Club length & 214 & 42.734 & 0.000 & 8.938 & 0.000 & 0.11650 \\
Sucker diam. & 225 & 32.102 & 0.000 & 16.178 & 0.000 & 0.00572 \\
Mantle circ. & 239 & 56.745 & 0.000 & 5.464 & 0.001 & 0.32683 \\
Gill length & 243 & 18.016 & 0.000 & 3.660 & 0.013 & 0.23385 \\
Funnel c. len. & 242 & 57.121 & 0.000 & 6.805 & 0.000 & 0.08653 \\
Nuchal c. len. & 239 & 15.153 & 0.000 & 9.150 & 0.000 & 0.12072 \\
Pen width & 242 & 15.446 & 0.000 & 12.286 & 0.000 & 0.09007 \\
\hline & & & & & & \\
\hline
\end{tabular}

Table A5

Analysis of covariance for morphometrics: female Loligo forbesi from February-April samples. Pen length is used as the covariate. For all variables, the table shows sample size, F-values and probabilities for tests of equality of adjusted means and equality of regression slopes. Probabilities are given to three decimal places. Pooled within-group regression coefficients are also given

\begin{tabular}{lllllll}
\hline Variable & $\mathrm{N}$ & \multicolumn{2}{l}{ Means } & & Slopes & $\begin{array}{l}\text { Regression } \\
\text { coefficient }\end{array}$ \\
\cline { 3 - 6 } Fin length & 203 & 15.278 & 0.000 & 1.727 & 0.163 & 0.70651 \\
\cline { 3 - 6 } Fin width & 202 & 54.354 & 0.000 & 0.123 & 0.946 & 0.55478 \\
Head length & 204 & 133.926 & 0.000 & 0.802 & 0.494 & 0.10544 \\
Head width & 193 & 9.421 & 0.000 & 1.125 & 0.340 & 0.09732 \\
Arm 1 length & 195 & 277.973 & 0.000 & 6.458 & 0.000 & 0.24681
\end{tabular}




\begin{tabular}{lllllll} 
Arm 2 length & 197 & 254.877 & 0.000 & 3.599 & 0.015 & 0.29822 \\
Arm 3 length & 195 & 300.238 & 0.000 & 1.320 & 0.269 & 0.31608 \\
Arm 4 length & 198 & 220.156 & 0.000 & 1.300 & 0.276 & 0.30316 \\
Tentacle length & 182 & 101.780 & 0.000 & 6.606 & 0.000 & 0.99726 \\
Club length & 177 & 114.320 & 0.000 & 4.472 & 0.003 & 0.23281 \\
Sucker diam. & 177 & 62.593 & 0.000 & 9.715 & 0.000 & 0.01120 \\
Mantle circ. & 204 & 149.972 & 0.000 & 0.273 & 0.845 & 0.44176 \\
Gill length & 201 & 14.660 & 0.000 & 5.321 & 0.002 & 0.23501 \\
Funnel c. len. & 203 & 125.441 & 0.000 & 2.661 & 0.049 & 0.09217 \\
Nuchal c. len. & 203 & 56.612 & 0.000 & 1.108 & 0.347 & 0.13800 \\
Pen width & 203 & 11.089 & 0.000 & 4.574 & 0.004 & 0.18271 \\
\hline
\end{tabular}

Table A6

Analysis of covariance for morphometrics: male Loligo vulgaris from February-April samples. Pen length is used as the covariate. For all variables, the table shows sample size, F-values and probabilities for tests of equality of adjusted means and equality of regression slopes. Probabilities are given to three decimal places. Pooled within-group regression coefficients are also given

\begin{tabular}{lllllll}
\hline Variable & $\mathrm{N}$ & \multicolumn{2}{l}{ Means } & & Slopes & Regression \\
\cline { 3 - 6 } Fin length & 135 & 2.708 & 0.048 & 0.302 & 0.824 & 0.70315 \\
\cline { 3 - 6 } Fin width & 135 & 3.469 & 0.018 & 0.886 & 0.450 & 0.52548 \\
Head length & 135 & 2.705 & 0.048 & 0.106 & 0.746 & 0.11242 \\
Head width & 95 & 55.588 & 0.000 & 3.144 & 0.029 & 0.06480 \\
Arm 1 length & 134 & 22.313 & 0.000 & 1.680 & 0.175 & 0.23994 \\
Arm 2 length & 135 & 17.359 & 0.000 & 1.547 & 0.206 & 0.28364 \\
Arm 3 length & 134 & 14.434 & 0.000 & 0.630 & 0.597 & 0.31229 \\
Arm 4 length & 134 & 17.463 & 0.000 & 0.089 & 0.966 & 0.25374 \\
Tentacle length & 95 & 12.151 & 0.000 & 1.608 & 0.193 & 0.79542 \\
Club length & 134 & 19.049 & 0.000 & 1.000 & 0.395 & 0.26361 \\
Sucker diam. & 128 & 13.604 & 0.000 & 1.652 & 0.181 & 0.01946 \\
Mantle circ. & 135 & 17.725 & 0.000 & 1.779 & 0.154 & 0.40286 \\
Gill length & 135 & 4.981 & 0.003 & 0.597 & 0.618 & 0.27786
\end{tabular}


$\begin{array}{lllllll}\text { Funnel c. len. } \quad 135 & 1.350 & 0.261 & 0.568 & 0.637 & 0.09673\end{array}$

$\begin{array}{lllllll}\text { Nuchal c. len. } \quad 135 & 4.089 & 0.008 & 0.826 & 0.482 & 0.13714\end{array}$

$\begin{array}{lllllll}\text { Pen width } & 135 & 2.711 & 0.048 & 1.116 & 0.345 & 0.10825\end{array}$

Table A7

Analysis of covariance for morphometrics: female Loligo vulgaris from February-April samples. Pen length is used as the covariate. For all variables, the table shows sample size, F-values and probabilities for tests of equality of adjusted means and equality of regression slopes. Probabilities are given to three decimal places. Pooled within-group regression coefficients are also given

\begin{tabular}{lllllll}
\hline Variable & $\mathrm{N}$ & \multicolumn{2}{l}{ Means } & & Slopes & Regression \\
\cline { 3 - 6 } & & $\mathrm{F}$ & $\mathrm{P}$ & $\mathrm{F}$ & $\mathrm{P}$ & coefficient \\
\cline { 3 - 6 } Fin length & 89 & 2.038 & 0.115 & 0.935 & 0.248 & 0.70027 \\
Fin width & 89 & 8.999 & 0.000 & 0.865 & 0.463 & 0.57405 \\
Head length & 89 & 3.284 & 0.025 & 0.400 & 0.753 & 0.14269 \\
Head width & 72 & 62.770 & 0.000 & 0.353 & 0.787 & 0.08750 \\
Arm 1 length & 89 & 15.819 & 0.000 & 3.189 & 0.028 & 0.30781 \\
Arm 2 length & 88 & 13.515 & 0.000 & 1.790 & 0.156 & 0.36765 \\
Arm 3 length & 88 & 21.738 & 0.000 & 2.517 & 0.064 & 0.36507 \\
Arm 4 length & 89 & 7.603 & 0.000 & 1.039 & 0.380 & 0.37505 \\
Tentacle length & 71 & 4.341 & 0.007 & 2.877 & 0.043 & 1.11556 \\
Club length & 89 & 19.345 & 0.000 & 2.766 & 0.047 & 0.37116 \\
Sucker diam. & 83 & 6.787 & 0.000 & 2.872 & 0.042 & 0.03162 \\
Mantle circ. & 89 & 7.430 & 0.000 & 2.053 & 0.113 & 0.48468 \\
Gill length & 89 & 12.454 & 0.000 & 3.558 & 0.018 & 0.29065 \\
Funnel c. len. & 89 & 0.286 & 0.835 & 1.471 & 0.229 & 0.11009 \\
Nuchal c. len. & 89 & 1.441 & 0.237 & 0.419 & 0.740 & 0.14541 \\
Pen width & 89 & 23.587 & 0.000 & 10.333 & 0.000 & 0.17662 \\
\hline
\end{tabular}

Table A8

Analysis of residuals for morphometrics: Loligo forbesi from February-April samples. For each variable, pooled-within group regressions on pen length were used. Residuals for each area are summarised as mean \pm SE 


\begin{tabular}{|c|c|c|c|c|}
\hline Variable & Aberdeen & Vigo & Lisbon & Azores \\
\hline \multicolumn{5}{|l|}{ (a) Males } \\
\hline Fin length & $-5.02 \pm 0.52$ & $-6.31 \pm 1.02$ & $-6.96 \pm 0.82$ & $13.16 \pm 1.77$ \\
\hline Fin width & $-20.36 \pm 1.07$ & $-12.50 \pm 1.58$ & $-10.93 \pm 1.60$ & $38.67 \pm 2.43$ \\
\hline Head length & $-11.47 \pm 0.38$ & $-7.75 \pm 0.62$ & $-1.76 \pm 0.74$ & $19.26 \pm 0.71$ \\
\hline Head width & $-3.12 \pm 0.36$ & $-2.57 \pm 0.46$ & $-1.54 \pm 0.51$ & $5.79 \pm 0.56$ \\
\hline Arm R1 length & $-20.87 \pm 0.68$ & $-15.84 \pm 1.09$ & $-14.13 \pm 1.23$ & $42.13 \pm 1.82$ \\
\hline Arm R2 length & $-23.51 \pm 0.79$ & $-18.57 \pm 1.00$ & $-15.79 \pm 1.29$ & $51.40 \pm 2.65$ \\
\hline Arm R3 length & $-24.65 \pm 0.82$ & $-22.79 \pm 1.25$ & $-20.35 \pm 1.56$ & $58.61 \pm 3.07$ \\
\hline Arm R4 length & $-21.42 \pm 0.65$ & $-22.48 \pm 1.13$ & $-20.94 \pm 1.51$ & $49.39 \pm 2.43$ \\
\hline Tentacle length & $-52.33 \pm 3.18$ & $-36.37 \pm 4.71$ & $-12.01 \pm 8.05$ & $112.60 \pm 8.22$ \\
\hline Club length & $-13.22 \pm 0.86$ & $-19.14 \pm 1.21$ & $-14.14 \pm 1.62$ & $32.21 \pm 2.05$ \\
\hline Sucker diameter & $-0.58 \pm 0.04$ & $-0.48 \pm 0.08$ & $-0.45 \pm 0.10$ & $1.16 \pm 0.08$ \\
\hline Mantle circumference & $-15.90 \pm 0.65$ & $-3.74 \pm 1.12$ & $-4.98 \pm 1.43$ & $26.57 \pm 2.28$ \\
\hline Gill length & $-4.07 \pm 0.45$ & $-4.91 \pm 0.74$ & $1.69 \pm 0.61$ & $6.69 \pm 1.18$ \\
\hline Funnel cart. length & $-2.92 \pm 0.17$ & $-1.33 \pm 0.30$ & $-0.23 \pm 0.29$ & $4.47 \pm 0.34$ \\
\hline Nuchal cart. length & $-2.57 \pm 0.23$ & $-2.53 \pm 0.28$ & $-1.07 \pm 0.45$ & $5.13 \pm 0.68$ \\
\hline Pen width & $-1.76 \pm 0.18$ & $-3.07 \pm 0.44$ & $-3.18 \pm 0.38$ & $5.55 \pm 0.60$ \\
\hline \multicolumn{5}{|l|}{ (b) Females } \\
\hline Fin length & $-3.69 \pm 0.60$ & $0.03 \pm 1.19$ & $-4.18 \pm 1.37$ & $9.46 \pm 1.27$ \\
\hline Fin width & $-9.47 \pm 0.89$ & $2.53 \pm 2.20$ & $-2.71 \pm 1.67$ & $18.75 \pm 1.52$ \\
\hline Head length & $-7.58 \pm 0.44$ & $-4.23 \pm 0.73$ & $-0.64 \pm 0.51$ & $15.62 \pm 1.03$ \\
\hline Head width & $-1.39 \pm 0.44$ & $1.23 \pm 0.93$ & $1.13 \pm 0.42$ & $1.77 \pm 0.34$ \\
\hline Arm R1 length & $-14.38 \pm 0.56$ & $-8.36 \pm 1.29$ & $-7.71 \pm 0.85$ & $31.55 \pm 1.15$ \\
\hline Arm R2 length & $-16.67 \pm 0.61$ & $-8.73 \pm 1.49$ & $-9.87 \pm 1.25$ & $38.56 \pm 1.49$ \\
\hline Arm R3 length & $-18.44 \pm 0.72$ & $-11.18 \pm 1.53$ & $-13.09 \pm 1.13$ & $45.32 \pm 1.48$ \\
\hline Arm R4 length & $-14.30 \pm 0.67$ & $-9.12 \pm 1.59$ & $-9.76 \pm 0.92$ & $34.83 \pm 1.33$ \\
\hline Tentacle length & $-31.67 \pm 2.64$ & $-4.37 \pm 7.00$ & $2.50 \pm 3.27$ & $71.07 \pm 4.18$ \\
\hline Club length & $-7.61 \pm 0.63$ & $-7.68 \pm 0.96$ & $-5.86 \pm 0.84$ & $22.47 \pm 1.07$ \\
\hline Sucker diameter & $-0.33 \pm 0.03$ & $0.27 \pm 0.06$ & $-0.16 \pm 0.08$ & $0.73 \pm 0.05$ \\
\hline Mantle circumference & $-10.20 \pm 0.56$ & $-3.36 \pm 1.24$ & $-1.49 \pm 1.06$ & $9.95 \pm 1.08$ \\
\hline Gill length & $-2.80 \pm 0.45$ & $-3.22 \pm 0.99$ & $-1.78 \pm 0.59$ & $7.25 \pm 1.29$ \\
\hline Funnel cart. length & $-2.16 \pm 0.85$ & $0.24 \pm 0.35$ & $-1.02 \pm 0.26$ & $4.67 \pm 0.21$ \\
\hline
\end{tabular}




\begin{tabular}{lllll}
\hline Nuchal cart. length & $-1.64 \pm 0.16$ & $-0.83 \pm 0.37$ & $-1.63 \pm 0.33$ & $4.40 \pm 0.25$ \\
Pen width & $0.96 \pm 0.18$ & $1.05 \pm 0.52$ & $0.15 \pm 0.36$ & $2.21 \pm 0.35$ \\
\hline
\end{tabular}

Table A9

Analysis of residuals for morphometrics: Loligo vulgaris from February-April samples. For each variable, pooled-within group regressions on pen length were used. Residuals for each area are summarised as mean \pm SE

\begin{tabular}{|c|c|c|c|c|}
\hline Variable & Aberdeen & Vigo & Lisbon & Azores \\
\hline \multicolumn{5}{|l|}{ (a) Males } \\
\hline Fin length & $2.79 \pm 0,69$ & $-0.82 \pm 0.89$ & $-0.41 \pm 0.70$ & $-3.05 \pm 1.30$ \\
\hline Fin width & $3.19 \pm 1,13$ & $-9.34 \pm 1.78$ & $0.23 \pm 1.15$ & $-2.12 \pm 2.78$ \\
\hline Head length & $-1.31 \pm 0.54$ & $-1.85 \pm 0.73$ & $0.81 \pm 0.51$ & $-3.23 \pm 0.43$ \\
\hline Head width & $1.20 \pm 0.52$ & $-2.56 \pm 0.81$ & $-1.44 \pm 0.24$ & $8.69 \pm 0.77$ \\
\hline Arm R1 length & $-4.10 \pm 1.14$ & $-12.53 \pm 1.67$ & $3.38 \pm 0.71$ & $-12.01 \pm 1.00$ \\
\hline Arm R2 length & $-4.05 \pm 1.23$ & $-13.75 \pm 2.52$ & $3.56 \pm 0.87$ & $-13.20 \pm 1.19$ \\
\hline Arm R3 length & $-4.44 \pm 1.35$ & $-15.30 \pm 1.95$ & $3.65 \pm 0.99$ & $-10.90 \pm 1.27$ \\
\hline Arm R4 length & $-3.62 \pm 1.40$ & $-15.12 \pm 2.21$ & $3.15 \pm 0.77$ & $-8.74 \pm 1.21$ \\
\hline Tentacle length & $-8.14 \pm 3.39$ & $-20.82 \pm 7.29$ & $13.58 \pm 3.40$ & $-37.43 \pm 3.56$ \\
\hline Club length & $-4.58 \pm 1.23$ & $-10.56 \pm 2.70$ & $4.13 \pm 1.05$ & $-21.28 \pm 0.81$ \\
\hline Sucker diameter & $0.84 \pm 0.13$ & $0.11 \pm 0.39$ & $-0.13 \pm 0.10$ & $-1.15 \pm 0.12$ \\
\hline Mantle circumference & $3.65 \pm 0.54$ & $-8.49 \pm 1.42$ & $0.23 \pm 0.52$ & $-4.51 \pm 0.88$ \\
\hline Gill length & $-3.34 \pm 0.75$ & $-0.61 \pm 1.38$ & $1.04 \pm 0.51$ & $-0.95 \pm 1.21$ \\
\hline Funnel cart. length & $0.09 \pm 0.39$ & $-0.97 \pm 0.35$ & $0.14 \pm 0.19$ & $-0.84 \pm 0.21$ \\
\hline Nuchal cart. length & $-0.55 \pm 0.34$ & $-1.09 \pm 0.45$ & $0.42 \pm 0.21$ & $-1.94 \pm 0.31$ \\
\hline Pen width & $-0.11 \pm 0.28$ & $-1.80 \pm 0.72$ & $0.24 \pm 0.20$ & $-0.37 \pm 0.46$ \\
\hline \multicolumn{5}{|l|}{ (b) Females } \\
\hline Fin length & $0,34 \pm 0.60$ & $-2.12 \pm 0.62$ & $0.75 \pm 0.67$ & $-1.27 \pm 2.04$ \\
\hline Fin width & $4.88 \pm 1.17$ & $-7.39 \pm 1.13$ & $0.23 \pm 1.22$ & $0.91 \pm 1.19$ \\
\hline Head length & $-0.10 \pm 0.70$ & $-0.09 \pm 0.83$ & $0.64 \pm 0.58$ & $-4.23 \pm 0.91$ \\
\hline Head width & $0.82 \pm 0.31$ & $-0.92 \pm 0.38$ & $-1.80 \pm 0.32$ & $8.26 \pm 0.98$ \\
\hline Arm R1 length & $-1.23 \pm 1.16$ & $-7.21 \pm 1.30$ & $3.20 \pm 0.57$ & $-1.05 \pm 3.14$ \\
\hline Arm R2 length & $-0.81 \pm 1.32$ & $-8.58 \pm 2.04$ & $3.82 \pm 0.79$ & $-4.26 \pm 3.43$ \\
\hline
\end{tabular}




\begin{tabular}{lllll} 
Arm R3 length & $0.60 \pm 1.27$ & $-11.82 \pm 2.28$ & $4.77 \pm 0.87$ & $-8.56 \pm 4.51$ \\
Arm R4 length & $1.41 \pm 1.08$ & $-5.86 \pm 1.70$ & $2.02 \pm 0.86$ & $-4.75 \pm 2.85$ \\
Tentacle length & $-3.93 \pm 3.47$ & $-4.76 \pm 6.08$ & $9.57 \pm 3.31$ & $-18.21 \pm 11.44$ \\
Club length & $-5.35 \pm 1.34$ & $-3.21 \pm 2.37$ & $5.06 \pm 0.85$ & $-11.50 \pm 2.18$ \\
Sucker diameter & $0.45 \pm 0.12$ & $0.66 \pm 0.23$ & $-0.25 \pm 0.13$ & $-0.75 \pm 0.38$ \\
Mantle circumference & $3.40 \pm 0.77$ & $-1.86 \pm 0.63$ & $-0.69 \pm 0.64$ & $-1.63 \pm 1.62$ \\
Gill length & $-3.48 \pm 0.59$ & $0.56 \pm 0.70$ & $1.54 \pm 0.46$ & $-1.11 \pm 2.14$ \\
Funnel cart. length & $-0.01 \pm 0.46$ & $0.23 \pm 0.30$ & $-0.12 \pm 0.19$ & $0.34 \pm 0.59$ \\
Nuchal cart. length & $0.05 \pm 0.33$ & $-0.49 \pm 0.66$ & $0.28 \pm 0.21$ & $-1.03 \pm 0.61$ \\
Pen width & $0.41 \pm 0.47$ & $0.96 \pm 0.57$ & $-1.23 \pm 0.25$ & $5.47 \pm 0.55$ \\
\hline
\end{tabular}

Table A10

Seasonal differences in Loligo forbesi from the Scottish west coast: summarised results from four-way analyses of vocariance. F-values and probabilities are tabulated for main effects only. Error degrees of freedom are tabulated; degrees of freedom for month, worker, sex and maturity are 2,1,1 and 1 respectively. The slope of the regression on the covariate $(\mathrm{PL})$ was always significant $(\mathrm{P}<0.0001)$. Significant effects $(\mathrm{P}<0.05)$ are indicated by probability values (to three significant places) in bold type

\begin{tabular}{|c|c|c|c|c|c|c|c|c|c|}
\hline \multirow[t]{2}{*}{ Variable } & \multirow{2}{*}{$\begin{array}{l}\text { Error } \\
\text { d.f. }\end{array}$} & \multicolumn{2}{|l|}{ Month } & \multicolumn{2}{|c|}{ Worker } & \multicolumn{2}{|l|}{ Sex } & \multicolumn{2}{|c|}{ Maturity } \\
\hline & & $\mathrm{F}$ & $\mathrm{P}$ & $\mathrm{F}$ & $\mathrm{P}$ & $F$ & $\mathrm{P}$ & $\mathrm{F}$ & $\mathrm{P}$ \\
\hline $\begin{array}{l}\text { Fin } \\
\text { length }\end{array}$ & 602 & 1.04 & 0.354 & 10.11 & 0.002 & 7.27 & 0.007 & 5.07 & 0.024 \\
\hline Fin width & 595 & 24.56 & 0.000 & 0.62 & 0.431 & 53.06 & 0.000 & 2.80 & 0.095 \\
\hline $\begin{array}{l}\text { Head } \\
\text { length }\end{array}$ & 597 & 8.04 & 0.000 & 0.04 & 0.835 & 7.54 & 0.006 & 35.31 & 0.000 \\
\hline $\begin{array}{l}\text { Head } \\
\text { width }\end{array}$ & 595 & 8.66 & 0.000 & 54.77 & 0.000 & 4.89 & 0.027 & 24.25 & 0.000 \\
\hline $\begin{array}{l}\text { Arm } 1 \\
\text { length }\end{array}$ & 579 & 14.86 & 0.000 & 2.63 & 0.105 & 0.99 & 0.321 & 0.68 & 0.410 \\
\hline $\begin{array}{l}\text { Arm } 2 \\
\text { length }\end{array}$ & 574 & 10.53 & 0.000 & 1.89 & 0.169 & 0.23 & 0.630 & 4.62 & 0.032 \\
\hline Arm 3 & 565 & 4.85 & 0.008 & 2.71 & 0.100 & 4.93 & 0.027 & 11.58 & 0.001 \\
\hline
\end{tabular}




\begin{tabular}{|c|c|c|c|c|c|c|c|c|c|}
\hline length & & & & & & & & & \\
\hline Arm 4 & 591 & 18.61 & 0.000 & 0.13 & 0.716 & 4.60 & 0.032 & 2.73 & 0.098 \\
\hline \multicolumn{10}{|l|}{ 1ength } \\
\hline Tentacle & 538 & 50.50 & 0.000 & 3.69 & 0.055 & 1.94 & 0.164 & 23.87 & 0.000 \\
\hline \multicolumn{10}{|l|}{ len. } \\
\hline Club & 499 & 31.99 & 0.000 & 0.07 & 0.793 & 4.14 & 0.042 & 10.48 & 0.001 \\
\hline \multicolumn{10}{|l|}{ length } \\
\hline Sucker & 533 & 58.41 & 0.000 & 3.14 & 0.076 & 13.75 & 0.000 & 10.86 & 0,001 \\
\hline \multicolumn{10}{|l|}{ diam. } \\
\hline Mantle & 602 & 31.01 & 0.000 & 3.91 & 0.048 & 72.23 & 0.000 & 115.17 & 0.000 \\
\hline \multicolumn{10}{|l|}{ circ. } \\
\hline Gill & 597 & 1.65 & 0.193 & 6.28 & 0.012 & 0.17 & 0.678 & 49.50 & 0.000 \\
\hline \multicolumn{10}{|l|}{ length } \\
\hline Funnel c. & 597 & 18.01 & 0.000 & 9.03 & 0.003 & 28.81 & 0.000 & 65.08 & 0.000 \\
\hline \multicolumn{10}{|l|}{ length } \\
\hline Nuchal c. & 599 & 13.66 & 0.000 & 2.15 & 0.142 & 2.57 & 0.109 & 96.99 & 0.000 \\
\hline \multicolumn{10}{|l|}{ length } \\
\hline Pen & 600 & 4.12 & 0.017 & 0.90 & 0.343 & 372.57 & 0.000 & 26.66 & 0.000 \\
\hline width & & & & & & & & & \\
\hline
\end{tabular}

Table A11

Multiple regression for morphometrics of male Loligo forbesi from the Scottish west coast

\begin{tabular}{llllll}
\hline Variable & Intercept & Pen length & Month & Worker & Testis length \\
\hline Fin length & -10.890 & 0.703 & 0.219 & -2.284 & - \\
Fin width & 3.277 & 0.495 & 1.308 & - & -0.132 \\
Head length & 16.553 & 0.123 & 0.531 & - & -0.091 \\
Head width & 2.490 & 0.088 & - & 2.186 & -0.035 \\
Arm 1 length & 5.246 & 0.211 & 0.743 & - & -0.061 \\
Arm 2 length & 10.273 & 0.260 & 1.035 & - & -0.078 \\
Arm 3 length & 19.246 & 0.296 & 0.856 & - & -0.124 \\
Arm 4 length & 10.440 & 0.252 & 0.978 & - & - \\
\hline
\end{tabular}




\begin{tabular}{llllll}
\hline Tentacle length & 52.539 & 0.843 & 4.468 & - & -0.326 \\
Club length & 15.949 & 0.210 & 1.189 & - & -0.100 \\
Sucker diam. & 0.340 & 0.011 & 0.070 & - & -0.003 \\
Mantle circ. & 29.761 & 0.448 & 1.736 & - & -0.184 \\
Gill length & 8.934 & 0.296 & 0.420 & -2.227 & -0.088 \\
Funnel c. length & 2.338 & 0.106 & 0.285 & 0.668 & -0.034 \\
Nuchal c. length & 2.068 & 0.163 & 0.422 & - & -0.052 \\
Pen width & 4.745 & 0.128 & 0.346 & - & -0.027 \\
\hline
\end{tabular}

Table A12

Multiple regression for morphometrics of female Loligo forbesi from the Scottish west coast

\begin{tabular}{llllll}
\hline Variable & Intercept & Pen length & Month & Worker & Nid. g.1. $^{\mathrm{a}}$ \\
\hline Fin length & -13.710 & 0.740 & - & -1.701 & -0.038 \\
Fin width & 0.945 & 0.546 & 0.161 & -3.061 & - \\
Head length & 11.631 & 0.168 & 0.184 & - & -0.132 \\
Head width & -0.573 & 0.116 & 0.118 & 2.182 & -0.059 \\
Arm 1 length & -1.751 & 0.258 & 0.344 & - & -0.065 \\
Arm 2 length & 0.140 & 0,331 & 0.407 & - & -0.099 \\
Arm 3 length & 1.094 & 0,373 & 0.407 & 3.460 & -0.133 \\
Arm 4 length & -2.936 & 0,367 & 0.570 & - & -0.131 \\
Tentacle length & -22.364 & 1.233 & 3.992 & - & -0.436 \\
Club length & 0.514 & 0,267 & 0.894 & - & -0.082 \\
Sucker diam. & -0.550 & 0,016 & 0.057 & - & -0.007 \\
Mantle circ. & 29.097 & 0.512 & 0.632 & - & -0.196 \\
Gill length & 6.567 & 0.308 & - & -1.074 & -0.097 \\
Funnel c. length & 3.063 & 0.111 & 0.111 & 0.686 & -0.037 \\
Nuchal c. length & 2.743 & 0.169 & 0.120 & 0.479 & -0.067 \\
Pen width & 4.922 & 0.140 & -0.223 & - & 0.088 \\
\hline Nidamental gand & & & & &
\end{tabular}

${ }^{a}$ Nidamental gland length.

Table A13

Analysis of covriance for morphometrics: male Loligo forbesi from Scottish samples 1990-1991. Pen length is used as the covariate. For all variables, the table presents 
sample size, F-values and probabilities for tests of equality of adjusted means and equality of regression slopes. Probabilities are given to three decimal places. The pooled-within group regression coefficients are also given

\begin{tabular}{lllllll}
\hline Variable & $\mathrm{N}$ & \multicolumn{2}{l}{ Means } & & Slopes & Regression \\
\cline { 3 - 6 } Fin length & & $\mathrm{F}$ & $\mathrm{P}$ & $\mathrm{F}$ & $\mathrm{P}$ & \\
\cline { 3 - 6 } Foefficient \\
\cline { 3 - 6 } Fin width & 448 & 5.817 & 0.000 & 2.992 & 0.000 & 0.69919 \\
Head length & 447 & 16.576 & 0.000 & 4.177 & 0.000 & 0.09770 \\
Head width & 443 & 6.759 & 0.000 & 5.114 & 0.000 & 0.07789 \\
Arm 1 length & 441 & 9.769 & 0.000 & 5.794 & 0.000 & 0.18518 \\
Arm 2 length & 437 & 13.519 & 0.000 & 7.773 & 0.000 & 0.22684 \\
Arm 3 length & 426 & 8.833 & 0.000 & 5.397 & 0.000 & 0.24836 \\
Arm 4 length & 441 & 12.067 & 0.000 & 8.214 & 0.000 & 0.23851 \\
Tentacle length & 412 & 14.685 & 0.000 & 3.947 & 0.000 & 0.69741 \\
Club length & 383 & 12.488 & 0.000 & 6.064 & 0.000 & 0.17172 \\
Sucker diam. & 409 & 15.854 & 0.000 & 14.690 & 0.000 & 0.00988 \\
Mantle circ. & 450 & 42.012 & 0.000 & 10.935 & 0.000 & 0.39002 \\
Gill length & 449 & 11.376 & 0.000 & 2.574 & 0.001 & 0.26317 \\
Funnel c. length & 445 & 21.481 & 0.000 & 5.339 & 0.000 & 0.09360 \\
Nuchal c. length & 447 & 26.510 & 0.000 & 11.588 & 0.000 & 0.14778 \\
Pen width & 450 & 17.189 & 0.000 & 12.589 & 0.000 & 0.12003 \\
\hline & & & & & & \\
\hline
\end{tabular}

Table A14

Standardized (by pooled within-group variances) coefficients for canonical variables

\begin{tabular}{lllll}
\hline Variable & \multicolumn{2}{l}{ All variables } & \multicolumn{2}{l}{ Excluding tentacles } \\
\cline { 2 - 5 } & CV1 & CV2 & CV1 & CV2 \\
\hline Fin length & 0.067 & -0.084 & 0.059 & 0.202 \\
Fin width & -0.217 & 0.292 & -0.190 & -0.121 \\
Head length & 0.162 & -0.284 & 0.176 & 0.504 \\
Head width & -0.013 & -0.087 & -0.044 & -0.108 \\
Arm 1 length & -0.211 & 0.496 & -0.137 & -0.142 \\
Arm 2 length & 0.177 & -0.505 & 0.182 & 0.622 \\
\hline
\end{tabular}




\begin{tabular}{lllll}
\hline Arm 3 length & -0.184 & -0.181 & -0.148 & -0.026 \\
Arm 4 length & 0.106 & 0.159 & 0.106 & 0.012 \\
Tentacle length & 0.193 & -0.539 & - & - \\
Club length & 0.060 & 0.058 & - & - \\
Sucker diameter & 0.066 & -0.388 & - & - \\
Mantle circumference & 0.733 & 0.191 & 0.763 & 0.224 \\
Gill length & -0.018 & -0.059 & 0.039 & -0.148 \\
Funnel cart. length & 0.188 & 0.565 & 0.195 & -0.605 \\
Nuchal cart. length & 0.209 & -0.006 & 0.240 & -0.058 \\
Pen width & -0.062 & 0.218 & -0.071 & -0.366 \\
\hline
\end{tabular}

